\title{
O conceito de cultura na intersecção de debates interdisciplinares: estudo de caso - a Aldeia Tapuia em Rubiataba, GO
}

\author{
The concept of culture in the intersection of interdisciplinary discussions: case \\ study - Tapuia Village in Rubiataba, GO \\ El concepto de cultura en la intersección de discusiones interdisciplinarias: \\ estudio de caso - el Pueblo de Tapuia en Rubiataba, GO
}

\author{
Valtecino Eufrásio Leal ${ }^{1}$ \\ Geruza Silva de Oliveira Vieira² \\ Helmer Marra Rodrigues ${ }^{3}$ \\ Maria Abadia da Silva ${ }^{4}$
}

\begin{abstract}
Recebido em: 25/10/2019; revisado e aprovado em: 16/09/2020; aceito em: 04/10/2020
\end{abstract}
DOI: http://dx.doi.org/10.20435/inter.v22i3.2786

\begin{abstract}
Resumo: A Antropologia criou um relevante enfoque conceitual e metodológico para a pesquisa voltada ao entendimento das formas culturais relacionadas aos saberes a respeito da saúde e do sistema jurídico. No mundo contemporâneo, a antropologia da saúde e a antropologia jurídica são esferas com diversas linhas teóricas e benefícios diversificados. Pela importância dessas e de outras circunstâncias, é necessário realizar debates a respeito do Povo Indígena Tapuia no Cerrado goiano, principalmente a fim de compreender como esse povo desenvolve-se culturalmente, supera e resiste aos conflitos e às disputas pela terra, e para entender o desenvolvimento dos costumes dessa gente. Na atual pesquisa, foi utilizado o método de pesquisa bibliográfica, descritiva, com caráter qualitativo, a partir de conversas em determinada comunidade. Acredita-se que a vivência do processo saúde-doença pelos indivíduos, sendo eles de aldeia indígena ou não, está enraizada em valores, crenças, práticas, representações, imaginários, significados, experiências individuais e coletivas, reafirmando o caráter sociocultural dos fenômenos que o compõem, além, é claro, de fatores biopsicológicos nele envolvidos. Conclui-se que adquirir conhecimento da história desses povos e procurar informações, sejam elas culturais, sejam elas jurídicas ou biológicas, que possam colaborar para uma comunicação e ação colaborativa mais contextualizadas, são pontes que necessitam ser estabelecidas para tornar mínima a distância entre agentes indígenas e não indígenas.
\end{abstract}

Palavras-chave: indígena; saúde; direito; antropologia.

Abstract: Anthropology has created a relevant conceptual and methodological focus for research aimed at the understanding of cultural forms related to knowledge about health and the legal system. In the contemporary world, health anthropology and legal anthropology are spheres with diverse theoretical lines and diverse benefits. Due to the importance of these and other circumstances, it is necessary to hold debates about the Tapuia Indigenous People in the Cerrado of Goiás, especially to understand how these people develop culturally, overcome and resist conflicts and disputes over the land, and to understand the development of the customs of these people. In the current research, we used the bibliographic research method, descriptive, with a qualitative approach, based on conversations in a certain community. It is believed that the experience of the health-disease process by individuals, whether they are in an indigenous village or not, is rooted in the values, beliefs, practices, representations, imaginary, meanings, individual and collective experiences, reaffirming the sociocultural character of the phenomena that compose it, besides, of course, to the biopsychological factors involved in it. In conclusion, acquiring knowledge of the history of these peoples and seeking information - whether cultural, legal, or biological, that can contribute to a more contextualized communication and collaborative action - are bridges that need to be established to minimize the distance between indigenous and not indigenous agents.

Keywords: indigenous; health; law; anthropology.

\footnotetext{
${ }^{1}$ Universidade Corporativa da Polícia Rodoviária Federal (UniPRF), Florianópolis, Santa Catarina, Brasil.

${ }^{2}$ Universidade Federal de Mato Grosso (UFMT), Cuiabá, Mato Grosso, Brasil.

${ }^{3}$ Universidade Evangélica de Goiás (UNIEVANGÉLICA), Anápolis, Goiás, Brasil.

${ }^{4}$ Faculdade Evangélica de Ceres (FECER), Ceres, Goiás, Brasil.
} 


\begin{abstract}
Resumen: La antropología ha creado un enfoque conceptual y metodológico relevante para la investigación dirigida a comprender las formas culturales relacionadas con el conocimiento sobre la salud y el sistema legal. En el mundo contemporáneo, la antropología de la salud y la antropología legal son esferas con diversas líneas teóricas y diversos beneficios. Debido a la importancia de estas y otras circunstancias, es necesario mantener debates sobre los pueblos indígenas Tapuia en el Cerrado de Goiás, especialmente para comprender cómo estas personas se desarrollan culturalmente, superan y resisten conflictos y disputas sobre la tierra, y para comprender el desarrollo de las costumbres de las personas de esta región. En la presente investigación, se utilizó el método de investigación bibliográfica, descriptiva, con carácter cualitativo, basada en conversaciones en una determinada comunidad. Se cree que la experiencia del proceso de salud-enfermedad por parte de los individuos, ya sea que se encuentren en una aldea indígena o no, se basa en valores, creencias, prácticas, representaciones, imaginarios, significados, experiencias individuales y colectivas, reafirmando el carácter sociocultural de los fenómenos que lo componen. Además, por supuesto, los factores biopsicológicos implicados en él. Se concluye que adquirir conocimiento de la historia de estos pueblos y buscar información, ya sea cultural, legal o biológica, que pueda contribuir a una comunicación más contextualizada y a una acción de colaboración, son puentes que deben establecerse para minimizar la distancia entre agentes indígenas y no indígenas.
\end{abstract}

Palabras clave: indígena; salud; ley; antropología.

\title{
1 INTRODUÇÃO
}

O presente ensaio visa analisar e compreender cultura específica, na perspectiva interdisciplinar, da Aldeia Tapuia, em Rubiataba, Goiás, numa conexão com linhas teóricas ligadas à antropologia, à saúde e ao Direito. O estudo pretende também delimitar a importância do fundamento da cultura aplicada, sob conotações garantistas de um grupo indígena com características peculiares e sob a tutela de um arcabouço de legislações favoráveis à sua preservação e proteção.

A antropologia da vitalidade será foco de investigação subjacente, pois, em qualquer ambiente comunitário, a saúde é fenômeno de preocupação acadêmica genérica que se insere como artefato da ciência que estuda o homem, perante dois sentidos de noções primordiais: o primeiro, de viés filosófico, que converge para o comportamento e observa o ser como indivíduo, em sua corporeidade dinâmica, com relevância no universo, historicamente; o segundo, à volta do saber humano em seu sentido cultural - ou que se origina dos costumes e das intercorrências a partir deles formulados -, instituidor de suas tradições de cuidado com a saúde e com as disfunções deste estado derivadas. Dessa forma, há uma pressuposição de que, em comunidades como essas, existem associações sanitárias fixadas por determinada cultura particular.

Na perspectiva antropológica desta intervenção investigativa, há desdobramento para insights jurídicos, a fim de proporcionar melhor compreensão da influência da norma positivada no contexto da abordagem. De fato, na linguagem jurídica existem fontes formais e materiais do direito, uma geradora e interdependente da outra, que regulam a convivência comunitária em todos os tipos de sociedade. Nesse sentido, como o indígena é parte fundamental da cultura nacional, como forma de resguardar esse patrimônio vivo, foram criadas leis específicas que conferem direitos e deveres a esses grupamentos humanos.

A narrativa científica também se ocupa de articulações interdisciplinares, cujo "[...] interesse se dirige para os confins e as confrontações mútuas entre as disciplinas; trata-se de um conhecimento dos limites ou de um conhecimento nos limites, instituindo entre os diversos ocupantes do espaço mental um regime de copropriedade, que fundamenta a possibilidade de um diálogo entre os interessados" (GUSDORF, 1995, p. 15). 
As bases do enfoque perpassam também pela antropologia da vitalidade e da doença, temáticas essas que se fortaleceram no Brasil em décadas mais recentes e destacam-se com trajetórias colaborativas, a entremear olhares limites contemporâneos, sobre as representações e atividades de saúde, o que também foi objeto de preocupação nos estudos de Alves e Rabelo (1998, p. 107).

Estas atividades, têm expandido compreensão das modificações culturais sobre as quais se levantam os grupos de características e atos sobre a saúde e doença, segmentados de variados grupos populacionais, e tem colaborado, em demasiada medida, de oposto aos conhecimentos epidemiológicos que tendem a discorrer o conteúdo "doença e cultura" em formas de uma associação externa, sujeito de projeção na expressão de circunstâncias condicionantes.

A gama de possibilidades da Antropologia fixou relevante perspectiva conceitual e metodológica para a pesquisa organizada das formas culturais relacionadas à saúde. Isso possibilita analisar relações entre os padrões de atividade, que sustentam a administração dos sistemas de prevenção, interferências terapêuticas, jurídicas e padrões culturais de comunidades. O eixo de sustentação dessas relações oferece parâmetros para modificação da circunstância sociocultural em variados sistemas de saúde (MARRONI, 2007).

A ciência da saúde, por sua vez, interliga-se a esse pensar antropológico (conhecimento do perigo, ideias sobre prevenção, compreensões sobre causas, ideias sobre tratamentos próprios) e daí resultam efeitos culturalmente elaborados e culturalmente compreendidos. A perspectiva qualitativa foi empregada para reconhecer e averiguar a mediação que as circunstâncias sociais e habituais executam na projeção, de modo a conceituar e atuar com base na saúde e na doença (UCHOA; VIDAL, 1994). Entende-se, nesse introito, que a perspectiva qualitativa é o foco da investigação e necessita ser centralizada para se avançar para o entendimento dos significados impostos pelos sujeitos às suas ações.

Nesta investigação, foi priorizado o método de pesquisa bibliográfica, desse viés antropológico e interseccionado, e as análises principais tiveram como objeto a Aldeia Tapuia, na cidade de Rubiataba, Goiás, a partir de conversas e experiências de uma das coautoras, havidas na região, em 2016.

Richardson (2003) descreve que, na pesquisa qualitativa, seu método não emprega um instrumental estatístico como base na análise de um problema, não pretendendo medir ou numerar categorias. Fachin (2005) complementa que as variáveis qualitativas são descritas analiticamente, e não por medidas ou números. Os atributos são aspectos qualitativos nas variáveis da pesquisa, e em sua descrição não se utilizam números. Isso não quer dizer que a quantificação não possa ser aplicada para se determiná-los.

A pesquisa sobre a Aldeia Tapuia teve maior ênfase em 2016, a partir de abordagens e conversas com membros da aldeia, no sentido de apurar, mediante observação participante, opiniões a respeito de alguns elementos importantes para os objetivos da investigação. Houve conversa com o cacique da aldeia (Welington Tapuia) e com uma enfermeira (Maria Abadia) que relatou a sua vivência profissional na localidade.

De posse dos resultados encontrados, com base no referencial teórico escolhido, foram formuladas inferências e interpretação dos referidos resultados frutos de relatos de opiniões. Como as informações colhidas foram de natureza qualitativa, a análise das informações aconteceram também de forma qualitativa, ou seja, não houve tratamento estatístico envolvido, porém um 
conjunto de procedimentos que visaram organizar as informações, de modo que se revelassem com objetividade e isenção. Os diálogos não tiveram a finalidade de documentar informações pessoais ou de identificação, apenas se pretendeu coletar dados dialógicos necessários ao cumprimento dos objetivos iniciais fixados.

\section{ANTROPOLOGIA DA SAÚDE E CONEXÕES COM OUTRAS CIÊNCIAS}

Para a vertente de subjetivação da Antropologia da Saúde, a doença não pode ser reduzida particularmente a uma peculiaridade orgânica. Por meio da via antropológica, subjaz uma distinção necessária entre a doença-processo e a doença-experiência, relacionando-as entre si. A primeira expressa a anomalia dos sistemas biológicos e/ou psicológicos, e a última significa a derivação do convívio psicossocial. Dessa maneira, a doença não é gerada apenas como resultado do sistema patológico (no sentido biológico), mas sim como fruto de uma formulação cultural (MACHADO, 2004).

As tensões a serem discutidas nesta abordagem pretendem revelar que o misterioso, o desconhecido, por vezes, vem a prejudicar e nada adiciona de valor ao padrão do quotidiano cultural. Dentro da Antropologia Aplicada, pode-se aferir que as sociedades, desde o início das conquistas pelas guerras, utilizaram-se do processo de aculturação e do etnocentrismo, que são, respectivamente, a imposição da cultura do conquistador ao conquistado e a desconsideração da prévia cultura do segundo a favor do primeiro (MARCONI; PRESOTTO, 2010).

Na Antropologia da Saúde, decorrem-se contextos sobre como proceder nos acontecimentos pontuais a respeito das doenças e dos indivíduos em momento de doença, e o intuito da ciência em questão é trazer soluções às causas do sofrer físico. Outra finalidade é admitir a verdade de que o dado mais expressivo e de maior valor para o ser humano vai além de seu corpo biológico, uma vez que o ser experimenta situações subjetivas singularizadas, mas isso o diferencia do todo coletivo, enquanto ser individual. E, ao mesmo tempo, insere-se a indagação de como fazer com que a ciência e suas intervenções possam introjetar melhoras nos sujeitos, seja para curá-los, seja para educá-los. Ainda, é uma das missões da antropologia direcionar os grupos para a aceitação de que cada sujeito se encontra inserido em redes, composições, maneiras de pensamentos coletivos que, até determinado ponto, norteiam o seu comportamento (RAYNAUT, 2006).

Discussões na área da sociologia de saúde são relevantes para se compreender que as doenças em grupos indígenas não têm origem ou vínculo de motivo apenas em face da condição financeira e social, mas também se relacionam com os cuidados médicos proporcionados. Consequentemente, com a exposição dos grupos e seus vínculos e estratificações sociais, haveria a percepção de que algumas doenças teriam nascedouro nas circunstâncias sociais artificialmente elaboradas (MACHADO, 2004).

De acordo com Uchôa e Vidal (1994), da mesma maneira que se faz indispensável reconhecer a cultura dos indivíduos para constatar se reagem de maneira parecida ou diferente perante as doenças, a morte e outras situações, é indispensável se averiguar a cultura. Assim, será possível notar as circunstâncias em que se relacionam os fatores de determinada doença e como projetar seu tratamento. Ao se observar as atividades e representações sociais, percebese que os diversos grupos étnicos demonstram fundamentos de saúde/doença, com demasiada variedade de causas, explicações e debates, muitos deles vinculados a entendimentos tradicionais, com terapias sem quaisquer ligações com o modelo oficial de saúde. 
Ao se conjugar ciências biológicas e sociais aplicadas nessa área, observa-se que a atuação do profissional da saúde ampara-se em direitos humanos. Na Constituição da República Federativa (BRASIL, 1988), em seu art. 5으, inciso III, está previsto que "Ninguém será submetido a tortura nem a tratamento desumano ou degradante". Disso se infere que é trabalho do enfermeiro e de outros profissionais da saúde, como o médico e o odontólogo, zelarem pela dignidade das pessoas submetidas aos seus cuidados.

De igual sorte, no direito, positivou-se a liberdade de expressão cultural (BRASIL, 1988). Portanto há a necessidade expressa de tolerância para com todos. Dessa forma, em quaisquer comunidades, as garantias fundamentais são de cunho obrigatório e não haveria justificativa aceitável deixar de se outorgá-las aos povos índios que possuem acervo cultural de grande dimensão, em relação à maioria dos demais brasileiros, maioria esta que, em regra, valora pouco ou quase nada o patrimônio cultural a sua disposição.

É preciso releituras e reaproximação das concepções da Grécia Antiga, onde o contexto cultural possuía alta significação, vinculada às indagações subjetivas do homem. Naquele sistema, o indivíduo praticava a própria natureza cultural, por meio do estudo da filosofia (entendimento de si próprio e do mundo) e da consciência da vida em sociedade. Em todas essas interpretações de cultura, prevalecia a ideia primordial de desenvolvimento, elaboração e execução (SILVA et al., 2008).

A expressão cultura, com origem no verbo latino colere, significa cultivar, gerar, honrar, zelar e cuidar. Originou-se no fim do século XI, para mostrar a cautela dos indivíduos com os deuses (culto), bem como a ponderação dos indivíduos com a natureza (agricultura). Criaram-se também cultos à religião e à terra, como costume pela produção de bens comestíveis (verduras, legumes, frutas, grãos etc.). Desse modo, o termo costume é prevalente quando se menciona a cultura do café, de soja e de trigo (SILVA et al., 2008).

Segundo Laraia (2009, p. 30), "a primeira definição de cultura foi formulada do ponto de vista antropológico, por Edward Tylor, que procurou demonstrar que a cultura pode ser objeto de um estudo sistemático", pois revela fenômeno natural que possui causa e regularidades, permitindo o estudo objetivo e a análise capazes de proporcionar a formulação de leis sobre o processo cultural e a evolução.

Assim, a cultura pode ser referida como um grupo de fundamentos, símbolos, conceitos e atos que padronizam uma sociedade e atingem o que idealizamos, realizamos e temos como componentes de um estrato social. Todas as comunidades, da pré-história até contemporaneamente, carregam uma cultura. E cada costume tem seus fundamentos e suas leis morais. Pode-se expandir, numa discussão mais filosófica, que o costume é o resultado proporcionado pelos grupos ao problema da existência. Uma finalidade que se expõe em modos de conhecimento (demasiados), paixão (pathos) e atos (ethos). Isto é, em formas de razão, afeto e atividade (SILVA et al., 2008).

Cultura é, portanto, um sistema de padrões de comportamentos socialmente transmitidos que servem para adaptar as comunidades humanas aos seus signos biopsicológicos. Esse modo de vida das comunidades inclui tecnologias e modos de organização econômica, padrões de estabelecimento de agrupamento social e organização política, crenças e práticas religiosas (LARAIA, 2009).

A cultura, patrimônio da humanidade, constantemente percebida como arte, é muito mais do que produto da atividade humana, ao longo de sua construção e capilarização pelo mundo.

É realidade dinâmica, sempre viva e, por isso mesmo, reveste-se das maiores significações e se manifesta diferentemente entre os vários e distintos grupamentos humanos. Não se pode 
pensar em cultura como realidade única e universal. Como criação do homem, ela é própria da humanidade e exprime o todo, mas é particular e original em cada ser e em grupos humanos na aventura do homem sobre o planeta Terra (JOSÉ NETO, 2004). Por isso, é preciso conhecer o potencial da educação como reprodutora da cultura do grupo social hegemônico e como força de articulação de propostas para transformação e mudança.

Laraia (2009) menciona que existem dois tipos de mudanças culturais que podem incidir em sociedade. A mudança interna que acontece de modo lento, originada da importância da própria sociedade que determina a modificação de seu padrão de comportamento, para melhor se ajustar ao meio em que se vive. O outro tipo de mudança é mais severa e advém especialmente do contato interétnico que se refere às relações e trocas em meio às etnias distintas.

A concepção antropológica pressupõe que, ao se deparar com costumes variados, não se procedam apontamentos de conceitos tomados com fundamento no próprio modo cultural, mas se observem as diversas culturas conforme seus próprios conceitos e entendimentos por meio dos quais demonstrem concepção de mundo único que auxilie suas atividades, saberes e atos. A esse sistema se denomina relativismo cultural. É ele que possibilita entender o porquê das tarefas e os segmentos atribuídos a elas de maneira racional, sem o fim de se classificá-los ou julgá-los, mas de identificá-los como distintos (LANGDON; WIIK, 2010).

Ao se refletir sobre a cultura como fato total e que, consequentemente, insere-se numa concepção de mundo dos indivíduos que a distribuem, auxiliando, dessa maneira, a outros, com seus saberes, atividades e atitudes, a situação da saúde e da doença fica compreendida na acepção de realização social. A doença e as cautelas para com a saúde são gerais na sociedade e existem em todas as áreas. Cada conjunto administra-se coletivamente - por meio de formas materiais, idealização e artefatos culturais - para entender e desenvolver atributos em relação às experiências ou momentos de doença e sofrimentos, sejam eles particulares, sejam eles coletivos (LANGDON; WIIK, 2010).

A cultura indígena, enquanto acepção multicausal admitida por todos os povos, está tangenciada também no âmbito do Direito Internacional, mais enfaticamente na Convenção 169 da Organização Internacional do Trabalho (OIT). Na introdução desta Convenção, incluiu-se a "[...] particular contribuição dos povos indígenas e tribais à diversidade cultural, à harmonia social e ecológica da humanidade e à cooperação e compreensão internacional" (MAZZUOLI, 2015, p. 1326). Ainda, consta do mesmo documento normativo internacional:

Artigo 5‥ Ao se aplicar as disposições da presente Convenção: a) deverão ser reconhecidos e protegidos os valores e práticas sociais, culturais religiosos e espirituais próprios dos povos mencionados e dever-se-á levar na devida consideração a natureza dos problemas que Ihes sejam apresentados, tanto coletiva como individualmente; b) deverá ser respeitada a integridade dos valores, práticas e instituições desses povos. (MAZZUOLI, 2015).

Dessa maneira, o raciocínio decorrente dessa previsão internacional, de qual o Brasil é aderente, é mais bem explicado pelo constitucionalista e ministro do Supremo Tribunal Federal Alexandre de Moraes, na obra "Direito Constitucional", ao asseverar que a

Constituição reconhece aos índios sua organização social, costumes, línguas, crenças e tradições, e os direitos originários sobre as terras que tradicionalmente ocupam, competindo à União demarcá-las, proteger e fazer respeitar todos os seus bens. (MORAES, 2003, p. 686). 


\section{VALORES HISTÓRICOS E GEOGRÁFICOS DA ALDEIA TAPUIA}

A partir do esboço desses delineamentos teóricos preliminares, pode-se considerar que o estudo da população indígena do Cerrado goiano e sua cultura busca identificar a particularidade histórica de cada um desses grupos e visa destacar a importância de se adequar as proporções históricas às dimensões espaciais. Essa narrativa nos leva à compreensão de que todos os povos estão ou ao menos deveriam se achar inclusos nesse escorço teórico, mas há conteúdos e multifaces únicas, pois cada população possui atributos peculiares à sua história, costume e espaço na rede distinta das áreas goianas (SILVA, 2013).

Pela importância dessas e de várias outras circunstâncias históricas e geográficas, priorizase uma rápida abordagem a respeito do Povo Indígena Tapuia, para se compreender como esse povo desenvolveu-se culturalmente e como superou e resistiu aos conflitos e disputas pela terra. É imperioso, ainda, entender o desenvolvimento dos costumes desse povo.

Tapuia, significa na língua Tupi, "bárbaro" ou "inimigo". Os Tupis eram povos que habitavam na Tapuiretama (no interior) de Tapuios ou Bárbaros. Seus grupos habitavam distantes uns dos outros e eram individualistas. Lutavam entre eles ou contra os Tupis (SILVA, 2013).

A Terra Indígena Carretão situa-se nos municípios de Rubiataba e Nova América, no Estado de Goiás, retirada 285 km de Goiânia, na área de Mato Grosso Goiano. A denominação deve-se à localização da Terra Indígena, entre o Ribeirão Carretão e a Serra Dourada. A aldeia é composta de duas glebas não contínuas, a 1, de 1.666 hectares, situa-se nos municípios de Rubiataba e Nova América, e a 2, de 77 hectares, no município de Nova América. As duas glebas perfazem 1.743 hectares. O acesso ao Carretão se dá partindo de Rubiataba, pela rodovia estadual GO 334, sentido Rubiataba-Mozarlândia, que passa por Nova América, segue até o entroncamento com a GO 156, esta última no sentido Crixás-Morro Agudo, e corta a Terra Indígena, ao lado de sua sede. Outra opção é utilizar a GO 434, até o distrito Waldelândia e seguir pela GO 156, em direção a Crixás (JOSÉ NETO, 2004).

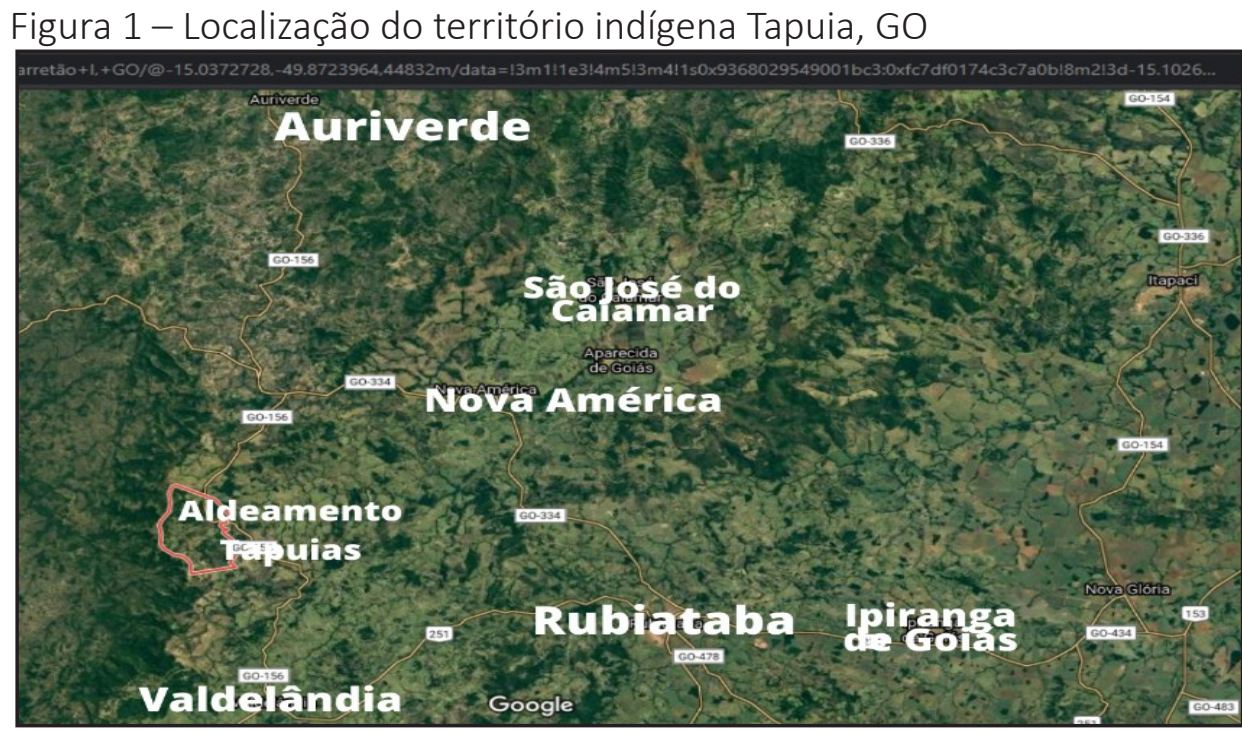

Fonte: Adaptado de Google (2020).

O solo na Terra Indígena Carretão é de baixa fertilidade e apresenta limitações para a utilização na agricultura. O Cerrado é a vegetação predominante, com algumas manchas de mata 
tropical às margens dos maiores cursos de água, os ribeirões Carretão e Carretãozinho. Grande parte da área situa-se em encostas da Serra Dourada, de acentuado declive, e serve apenas para pastagens, por apresentar solos rasos e cascalho (JOSÉ NETO, 2004).

As poucas áreas de relevo plano são adequadas para utilização agrícola mais intensiva, em virtude do que, entre os tapuios, predominam as atividades relacionadas à agricultura de subsistência e as pastagens, com técnicas rudimentares de trabalho braçal, quase sempre em pequenos mutirões organizados pelo grupo. O principal curso d'água que banha a Terra Indígena é o Córrego Carretão, que, mais abaixo, após deixar a área, passa a chamar-se Rio São Patrício. Pequenos córregos, como o do Macaco, o dos Passarinhos, o da Lajinha nascem ao pé da Serra Dourada e deságuam no Carretão.

O Córrego do Carretãozinho (ou Retiro) banha o limite sul da gleba 2 e deságua no São Patrício. À época da fundação do Aldeamento do Carretão, a região não era habitada por índios e nem fazia parte das áreas de mineração. Sua construção, além de favorecer o deslocamento dos índios das áreas de mineração, deve-se à localização estratégica, às margens da principal estrada que ligava a então capital da província de Goiás - atual cidade de Goiás - às regiões garimpeiras de Pilar, Crixás, Amaro Leite e norte da província e do País (JOSÉ NETO, 2004).

O povoado começou a ser ansiosamente demandado pelos itinerantes, em montarias ou carroças, para repouso e permuta de animais tracionadores. Em conformidade com notificações que se tem a respeito do povo Tapuia e em contextos do Barão de Mossâmedes, o início étnico está imbricado nos primordiais habitantes do aldeamento Carretão ou Pedro II, projetado na região central da Província de Goiás, em 1788, para acolher os índios Xavantes no segundo tempo da política de elaboração de povoados oficiais, quando a agropecuária já se incluía em Goiás, trocando o decaído período da mineração de ouro (SILVA, 2013).

A população do Carretão, nome da Terra Indígena Tapuia, como consta em pesquisas de diversos autores, sofreu graves reveses, como fome, doença, medicação prejudicial e até tormento por meio dos empregados do povoamento. Darcy Ribeiro (1979, apud JOSÉ NETO, 2004) menciona que a população do Carretão teve de habituar-se intimamente com ornamentos militares e testar a vida civilizada. Os tapuios são a consequência da mescla de costumes em suas etapas de vida. Descendem de várias etnias indígenas que transpuseram a colonização e povoaram aquela área em mescla com grupos humanos que para lá fugiram, como negros foragidos da escravidão das minas de ouro e, sucessivamente, já no começo do século XX, moradores migrantes nascidos em Goiás e Estados próximos (JOSÉ NETO, 2004).

Tapuio não é termo denominado de uma etnia. É muito mais uma demonstração usada por outros habitantes da região do que o autorreconhecimento, pois tanto os documentos históricos quanto o costume oral declaram um procedimento étnico de índios Xavantes, Xerentes, Javaés e Carajás que foram levados para a área depois do último quartel do século XVIII. Dessa forma, a expressão tapuio ou tapuia não é proveniente do povoado indígena do Carretão, mas já era usado antes mesmo de o Brasil ser afetado pelas caravanas portuguesas. Era nesse contexto que os índios tupis mostravam e apontavam os que não faziam parte de seu grupo familiar, ou melhor, os que faziam parte de outras linhagens, os que moravam nas áreas afastadas do litoral, os lutadores com os quais os outros não se falavam por expressarem uma língua distinta (JOSÉ NETO, 2004).

No Carretão, com o decorrer do tempo, o contexto tapuio começou a constituir os componentes de linhagem indígena. Apesar de que, no começo, durante aquisições dos períodos da colonização, tapuio era o contexto mencionado pelos habitantes do Carretão, no Estado de 
Goiás, independentemente do uso da expressão em circunstâncias diferentes, tendo como exemplo a designação de outros conjuntos indígenas de outras localidades do Brasil (JOSÉ NETO, 2004).

A edificação do povoamento Carretão ocorreu no segundo período, em consequência do contemporâneo ciclo financeiro e do comércio fluvial que demandavam a modificação dos lugarejos em povoados. Foi projetado para acolher os índios xavantes, que causavam temor aos habitantes do centro e do norte da província. Era necessária a captura desses índios hostis que impediam, com seus ataques, o fortalecimento de núcleos populacionais na região. $A$ finalidade era doutrinar indígenas não civilizados. Isso seria o fundamento dos contemporâneos povoamentos e, inclusive, havia a pretensão de mão de obra para a agricultura regional. Diversas bandeiras foram administradas para essa conquista, mas sem efeitos (JOSÉ NETO, 2004).

Pelas descrições dos tapuios mais velhos, acumuladas por antropólogos, primordialmente Lazarin (1985), isso implica essencial relevância para a reconstituição da história do povoamento objeto de estudo e sua harmonização com o grupo contemporâneo. Lazarin (1985, p. 41) reconhece duas linhagens de descrições: a primeira que constitui um passado mais distante (da "aldeia velha" ou da fazenda de escravos sem possuinte e desapropriada), explicada por diversas linhagens que se agruparam; e outra que estipula a derradeira e mais atual maneira de ocupação, considerada pelo modo como vem se expondo a experiência (concepção e favorecimento) de cada indivíduo.

Antropólogos e outros estudiosos localizaram, no fim da década de 1970 e origem dos anos 1980, diversos tapuios idosos que desempenhavam o vínculo de relação entre as linhagens modernas e os membros originários da histórica aldeia do Carretão. Conforme Lazarin (1985), os mais velhos componentes, Manuel Simão Borges de Aguiar, que certificou ter 97 anos em 1980, era confidente de relevantes lembranças fundamentadas em tapuias velhas, provavelmente as duas índias mencionadas nas últimas descrições provinciais, unidas com negros migrados das minas de Pilar, que deram início a famílias novas (JOSÉ NETO, 2004).

\section{A HUMANIZAÇÃO NO TRATO COM COMUNIDADES INDÍGENAS E A PRESERVAÇÃO DE SEUS VALORES CULTURAIS}

Um dos objetivos desta pesquisa é despertar o leitor para os desafios profissionais na prestação de políticas de saúde e jurídicas aos indígenas, o que, além de permitir a mudança das atividades de rotina, pode, na área da prevenção e do cuidado, conferir maior humanização a esses povos. A socialização, que até então estava vinculada às organizações religiosas, filantrópicas e paternalistas, teve o seu fundamento alterado no transcorrer dos últimos anos. Contemporaneamente, está compreendida como a eficácia de proporcionar atendimento de qualidade, associado às melhorias tecnológicas que proporcionem abrigo, cuidados e a execução de atividades cíclicas pelos agentes envolvidos (SILVA; SILVEIRA, 2011).

Nesse contexto, o humanizar se relaciona à oportunidade de modificação cultural da administração e das atividades desenvolvidas nas associações de saúde, admitindo-se padrões éticos, de respeito e reverência ao outro, de cuidado com a pessoa na convivência e, nessas circunstâncias, o profissional tende a ser compreendido como um membro, e não somente um consumista de trabalhos de saúde ou de outra ordem (FORTES, 2004).

Não obstante as melhoras e os avanços das últimas décadas, a atenção à saúde dos conjuntos indígenas foi permanentemente não organizada e esporádica. Mesmo com a geração 
do Serviço de Proteção aos Índios (SPI), não se estabeleceu maneira alguma de auxílio ou de trabalhos sistemáticos nessas comunidades.

Na pesquisa realizada por Palheta e Ferreira (2011) a respeito da tarefa dos agentes de saúde em comunidades indígenas no Amazonas e sua sensibilização com a cultura Yanomami, demonstrou-se que $a$ atenção às distintas culturas tornou-se controversa na forma e no controle dos fundamentos éticos. Os pesquisadores citados advertem que as atividades de saúde não devem ser direcionadas para mudanças de comportamento cultural ou de valores éticos, ainda que alguns comportamentos repercutam em índices de letalidade. Com essa ressalva, os autores buscam argumentar que as culturas das comunidades devem ser respeitadas, sempre.

O trabalho de profissionais da saúde, notoriamente aqueles da enfermagem que atuam de modo mais direto nesse contato, é tarefa primordial em tribos e aldeamentos indígenas. Essas atividades colaboram com a redução dos impactos de vários males de saúde, quando elaboradas de modo adaptado, e, no mais, intensificam o aconchego entre o enfermeiro e paciente, indígena ou não (BARROS, 2002). Mas esse profissional deve ser escolhido entre aqueles que possuam formação humanística generalizada, diante das múltiplas necessidades desses povos e por significar um vínculo direto entre eles e os meios urbanísticos.

Dessa forma, diante da gama inesgotável de culturas, o Brasil tem um compromisso de difícil missão para a atuação de profissionais de várias áreas do saber, e estes vivenciam diferenças interculturais extremamente desafiadoras, principalmente quando a questão abrange a saúde, a história e os direitos da população indígena. Mesmo perante previsões constitucionais da Carta Política do país de 1988, existem ainda sérias dificuldades a serem superadas na atenção a esses povos.

Como fator de agravamento da perda das culturas indígenas próprias, o desenvolvimento demográfico da sociedade indígena brasileira ampliou-se, conforme o Instituto Brasileiro de Geografia e Estatística (IBGE). O Censo 2010 contabilizou 896 mil indivíduos que se estabeleciam ou se consideravam indígenas; 572 mil, ou 63,8\%, habitavam no meio rural; e 517 mil, ou 57,7\%, habitavam em Terras Indígenas administrativamente identificadas (IBGE, 2010).

Em demanda executada pelo Departamento de Assuntos Indígenas (DAI), inferiu-se que 111 linhagens estão urbanizadas ou em vias de urbanização, e isso envolve 340 culturas e 181 línguas indígenas mencionadas no país; destas, 132 etnias são emissoras de português (LIDÓRIO, 2010).

Dessa forma, para comunidades não urbanizadas, o desafio que se coloca para os profissionais das ciências biológicas e sociais aplicadas está na aproximação para outorga de direitos e cuidados médicos. Os agentes de saúde, em regra, aproximam-se mais e devem operar nesse elo, além de proporcionar assistência aos povoamentos nesse espaço de larga variedade cultural, seja por meio das línguas, seja por meio das cores ou culturas. Nesses ambientes, os atores estão se habituando contemporaneamente, numa difícil missão da associação intercultural, da história, da concepção de mundo etc. (SILVA, 2013).

Associada à variedade cultural demonstrada por esses povoamentos, nota-se ainda uma voragem desses valores, diante da concepção de mundo dos agentes participantes; os prestadores de serviços são induzidos pelo entendimento ocidental da concepção dividida; e os Povos Indígenas, por sua vez, são absorvidos pela interpretação de mundo mais abrangente e integral (VERANINI; MORGADO, 1991). Os signos, que aos poucos convergem para novas concepções, provocam um deslizamento simbólico dos valores culturais, ainda que não existam opressores e oprimidos. Portanto, se grupos urbanizados - por hipótese, os agentes 
de saúde - creem que a dicotomia fixa prejuízos aos indígenas, paulatinamente, até mesmo de modo não impositivo, podem inserir/introduzir a própria cultura. De outra parte, na crença de que seu modus vivendi depende de uma virada comportamental e que, assim, as melhoras se ampliarão, os indígenas podem ceder espaço. No fim, bem ou mal, as culturas dos povos mais fragilizados tendem a se perder.

É fato que no Brasil há um panorama favorável ao sistema de urbanização, e isso inclui os povoamentos indígenas cada vez mais no processo de saúde nacional, já que, uma vez habitando nas cidades próximas de suas aldeias, procuram atendimento primordialmente em hospitais e em estações de saúde da rede pública. Os acontecimentos sociais, a associação e a migração dos povoamentos indígenas para cidades mais próximas, inclusive, têm trazido implicações graves nas situações de saúde/doença (COIMBRA; GARNELO, 2003).

Consequentemente, o argumento que se dialetiza envolve um reforçar do atendimento à saúde indígena em seus próprios ambientes, e isso deve ser pensado no âmbito interdisciplinar, com alguma preponderância para os enfermeiros ou agentes de saúde, pois esses profissionais, no modelo brasileiro, detêm intenso poder de agenda em áreas e terras indígenas. Não se pode afirmar, por evidente, que exista um subcampo para entendimentos antropológicos da saúde indígena ou que haja fundamentos, situações bem definidas e literaturas teóricas determinadas. Isso estaria em consonância com a orientação da antropologia brasileira, que tem evoluído no âmbito de recortes que levam à fragmentação da aproximação antropológica, levando a convergências diversas entre artefatos minuciosos e situações etnográficas (TEIXEIRA; SILVA, 2013).

\section{A CULTURA DOS TAPUIAS}

Na questão indígena da Aldeia Tapuia, percebe-se, a partir de sua história, que o tratamento digno e humanizado a esses Povos Indígenas levou a ótimos resultados. As trajetórias da comunidade apontam para a luta pela terra e por uma identidade étnica infringida pela influência de interesses econômicos de fazendeiros da região, e, em determinado momento do aldeamento, isso gerou reconfiguração de suas práticas culturais.

Nesse início do terceiro milênio, a língua do povo Tapuia é o português. Ritmada e agradável, cheia de encantos e de elevada capacidade para receber o outro. Esse povo tem fortes ligações com o lugar e, além disso, apresenta cuidados universais de cultura, no modo de falar, na batalha pela terra, na luta pela vida saudável e no anseio de Políticas Públicas eficazes e garantistas. Constatou-se também que o nome Tapuia, inicialmente, foi um estigma utilizado por fazendeiros, para, desse modo, recusar a identidade indígena.

As casas dos tapuias são erguidas de maneira bem parecida com a de um camponês. São afastadas uma das outras e, em meio a elas, são desenvolvidas pequenas atividades agrícolas. Existe uma grande utilização dos quintais com hortas e, na maioria das vezes, são as mulheres que plantam e cuidam.

Em conversa com o cacique da aldeia dos tapuias, foram relatadas experiências vivenciadas com lutas, dificuldades e preconceitos, mas eles sempre atuaram pela harmonia dos grupos ao longo dos anos.O cacique relatou fatores históricos, econômicos, sociais e culturais, que acabaram modificando a estrutura familiar. Em diálogos com a enfermeira coautora deste artigo, ela demonstrou a preocupação de transmissão das histórias de vida e do seu ensinamento para os grupos (conversas havidas com a enfermeira Maria Abadia da Silva, em 2017). 
Com base na autoconfiança, o cacique assim relatou: "Minha vida adulta aconteceu cedo, sem escola ou alguém que pudesse me alfabetizar". Ao abordar "sobre a cultura, ele declarou: "Temos ligação com a terra, a mãe e o aconchego da aldeia, o lugar de convivência e segurança. Nosso lugar é esse chão onde fazemos nossos rituais". Para os grupos indígenas, afirmou algumas vezes "[...] que a transmissão das vivências passadas é o mais importante". Disse também que as histórias são contadas e recontadas ao longo dos anos. Além de ensinar aos membros, essas histórias ajudam a preservar a cultura indígena (conversas havidas com a enfermeira em 2017).

De idêntica forma, a profissional que atuava na localidade, em 2016, relatou sua experiência vivida na Aldeia Tapuia durante quatro anos. Ficou claro que essa experiência não teria sido possível se ela não tivesse usufruído da confiança e do apoio dos tapuias. Isso fortaleceu o acolhimento entre enfermeira e pacientes. Para ela, "[...] trabalhar de acordo com a realidade local foi um grande desafio, pois levou improvisação ao lugar, ao atuar num posto avançado de saúde".

Porém relatou que havia dificuldade para exercer o ofício como enfermeira, mas viveu momentos de profunda aprendizagem em sua atuação profissional. Em dado momento durante a conversa, pôde-se observar que os tapuias têm grande poder de concentração e que mínimos afazeres Ihes tomam todo o tempo, e o fim é a obtenção do melhor resultado possível.

A profissional constatou também "[...] que ao se empenharem numa tarefa, os indígenas empreendem todos os esforços e atenção". Por isso ela agiu com cuidado, paciência e resiliência, pois, para o Tapuia, não existia regra ou hora para a busca de atendimento. Até que tentou, mas não houve ajuste com bons resultados, pois os tapuias se habituaram a procurar o serviço a qualquer hora, independentemente do caso ser emergencial ou não.

Ao retornar à aldeia com os demais pesquisadores após esses quatro anos, a enfermeira coautora observou que "[...] os tapuias já não são os mesmos de tempos atrás. Hoje, eles estão mais 'civilizados', sendo esse um dos pontos de avanço, em sua perspectiva. Interpretou-se que o termo civilizado foi empregado no sentido de um processo de sincretismo, por meio de qual os tapuias o agregaram à Língua Portuguesa, hoje dita materna pelo povo, mas, quanto à cultura deles, não houve ainda uma superação ou o esquecimento do próprio dialeto. Informou ainda que "os atendimentos de saúde, atualmente, são feitos pelos profissionais no posto avançado na aldeia, e os exames são realizados de acordo com o diagnóstico específico dos pacientes". Igualmente, na conversa, relatou que "O atendimento médico acontece uma vez por semana. São realizadas palestras, atividade de promoção de saúde, prevenção de doenças com profissionais de saúde que atuam na área e ações voltadas para a atenção básica".

Ainda, ressaltou:

Quando as doenças são mais graves, os doentes são encaminhados para as cidades de Nova América, Ceres, Rubiataba ou Goiânia. Eles não são refratários ao tratamento. Porém há resistência de algumas mulheres à realização do exame preventivo. No entanto acredita-se que a não aceitação desses exames e tratamentos específicos se dá pelo simples fato do medo do desconhecido.

Os autores deste trabalho, numa visita domiciliar à aldeia, assistiram a procedimento num paciente que estava acamado com câncer no esôfago, em qual fora introduzida uma sonda nasogástrica. Reafirmou a enfermeira, na conversa, que

São realizadas também visitas domiciliares às pessoas idosas e que as vacinas de crianças acontecem no posto de saúde de Rubiataba. Outras vacinações se dão no posto da aldeia, tais 
como as campanhas para adultos, porque o refrigerador disponível não comporta o quantitativo ideal de vacinas. E disse ainda que, se alguém precisar de curativos, esses são realizados nos postos de saúde e, às vezes, domiciliarmente, de acordo com o grau de contaminação.

Em sua observação, notou que "A manutenção da horta e a aquisição de insumos para preparação de medicamentos alternativos acontecem pelo povo, no próprio Cerrado. Mas isso não impede que eles compareçam às consultas médicas. Contudo é impossível considerar o Tapuia como um ser isolado". Ou seja, esse povo tem necessidade de cuidado, sem impor sua cultura. Na leitura da enfermeira, existem várias formas de se contribuir com a cultura dos tapuias, "[...] o respeito e o cuidado humanizado são as principais". Há também, na visão dela,

[...] a dificuldade enfrentada pelo grupo na compra de medicamento e na realização dos exames, pois, às vezes, o posto de saúde não fornece tais procedimentos e nem a medicação necessária. Quanto ao transporte para os centros urbanos, isso se dá por conta deles próprios e nem sempre há disponibilidade.

$\mathrm{Na}$ avaliação final da profissional de enfermagem, ficou claro que saber trabalhar em equipe, aceitando críticas, sugestão e ajuda, é muito importante para o bom andamento dessa modalidade de atividade em ambientes pouco explorados. E o profissional precisa estar preparado para atuar na atenção básica de saúde indígena, a fim de fortalecer a cultura dessa população. A profissional ouvida ressaltou que adquiriu muito conhecimento e aumentou o seu aprendizado com o trabalho adquirido com os tapuias e que se sente feliz pela experiência que a levou a ver a vida de modo diferente e com mais amor ao próximo.

Desses diálogos, apreende-se que a vivência do processo saúde-doença experimentada pela população indígena, está enraizada em valores, crenças, práticas, representações, imaginários, significados, experiências individuais e coletivas, reafirmando-se o caráter sociocultural desses fenômenos que o compõem. Além disso, ficaram evidentes os fatores biopsicológicos envolvidos nas relações.

Observa-se que o campo da antropologia da saúde, ao valorizar as muitas interpretações do fenômeno saúde/doença, procura entender as formas por meio das quais os indivíduos expressam e interpretam o sofrimento e a dor, bem como os sistemas terapêuticos. Emparelhada a essa vertente, está a parte cultural que deve ser resguardada e protegida pelo arcabouço normativo e jurídico. É necessário e possível conferir dignidade ao indígena, mas também é urgente criar intersecções entre áreas do saber, a fim de se defender e tutelar a concepção de cultura dessa gente. Não se deve permitir, em hipótese alguma, o abandono e o esquecimento de seus costumes e crenças.

\section{CONSIDERAÇÕES FINAIS}

No século XXI, o que se nota na comunidade Tapuia é o sinal de duas palavras que se sobrepõem: resiliência e esperança. O povo Tapuia possui resistência às entranhas de um tempo histórico, marcado por massacres e desrespeito aos indígenas, e se transformam, a cada desafio, em atores principais de seus planos de futuro.

É de se ressaltar que existe enorme carência de pesquisas que contribuam para o desenvolver de caminhos interculturais, entremeados ao respeito e à proteção dos valores fundamentais para a coexistência das populações indígenas. Percebeu-se, no entanto, que existe boa quantidade de profissionais de saúde, especialmente na área de enfermagem, atuando em

INTERAÇÕES, Campo Grande, MS, v. 22, n. 3, p. 755-771, jul./set. 2021. 
regiões e comunidades indígenas, mas muitos se veem insatisfeitos com o modo de acolhimento e atendimento dessa parcela da população brasileira. Portanto um grande desafio há de ser enfrentado, a fim de que esses profissionais se sintam capacitados do ponto de vista antropológico e jurídico para agirem e atuarem junto a esses povos.

Na realidade, além da perda cada vez mais expressiva do território e de sua cultura, que atingiu de modo considerável a vida dos tapuias, estes acabaram adquirindo dois olhares um sobre a terra e outro para a saúde-doença. Quanto à terra, estimam como o lugar onde se deu o nascimento de seus pais e avós, onde cresceram e viveram suas histórias e biografias. No aspecto da saúde-doença, nota-se nos dias atuais que a população indígena pesquisada procura por direitos e atenção à saúde diferenciada.

Em meio ao fazer profissional eminentemente técnico, existe a possibilidade de se desenvolver tecnologias de cuidado que assegurem o convívio e o respeito às diferenças, em suas subjetivações. Uma perspectiva diferente é o cuidar, em termos genéricos e interdisciplinares, a fim de focalizar o sentido de promover a vida, o potencial vital, o bem-estar dos seres humanos na sua individualidade, complexidade e integralidade, seja em aldeia indígena, seja em qualquer outra comunidade. Da mesma maneira, no cenário da povoação em questão, o Direito enquanto mecanismo ou ciência de acesso às garantias individuais e coletivas deveria se achar ao alcance da comunidade, para amparo e resolução dos conflitos por eles vivenciados, o que não ocorre, muito provavelmente, pela dificuldade, inclusive de transporte, para o acesso aos centros urbanos, implicando um reduzido contato com os profissionais dessa área.

Ressalte-se que os profissionais das ciências biológicas e das ciências sociais aplicadas, em específico os da saúde, da antropologia e do Direito, ainda não atuam com o fôlego devido perante a população indígena citada. Por essa razão, é essencial ir até essa gente e procurar compartilhar do conhecimento tradicional, a fim de descobrir espaços na Constituição Federal, em normas positivadas e no combinar de ações interdisciplinares que auxiliem e colaborem com esse viver em comunidade, nesta sociedade brasileira que é cada vez mais intercultural. Porquanto, se as diferenças fazem parte do dia a dia do indígena, estas mesmas diferenças nos induzem, de modo contínuo, a refletir sobre a relação com o outro.

O receptáculo do bem-estar social, espiritual, físico e mental das pessoas é a sociedade em que vivem, mas as comunidades neoliberais podem e devem atuar, para que outras ainda vulnerabilizadas acessem também as melhorias tecnológicas, sociológicas, de saúde e jurídicas criadas ou inventadas pelas primeiras. Nessa conjunção microssocial e intersubjetiva, os indígenas de aldeias como os tapuias são humanos com oportunidades de escolhas racionais. Muitos deles estão à procura de qualidade de vida para si, como pessoas, e para suas famílias. Percebeu-se, neste estudo, que na aldeia se busca a saúde, a educação e a tutela de seus direitos. Compete ao Estado e às comunidades mais avançadas responder de modo intercultural a esse chamamento e a essas necessidades fundamentais.

No contexto desse esboço científico, entendemos que adquirir conhecimento da história desses povos e procurar informações que possam colaborar para uma comunicação e ação mais contextualizadas são pontes que comumente necessitam ser estabelecidas para se reduzir a distância entre agentes indígenas e não indígenas. Desse modo, os dois lados contribuirão e retribuirão, uma vez que ora se aprende, ora se ensina nas experiências das diferenças indígena. As distintas visões de mundo existentes em nosso país têm a capacidade de nos proporcionar ainda mais riqueza, a partir da compreensão e da tolerância, visto que 
é indispensável uma comunicação intercultural e interdisciplinar mais humana, cuidadosa e, por conseguinte, acessível e dialógica.

\section{REFERÊNCIAS}

ALVES, Paulo César B.; RABELO, Miriam Cristina M. (Org.). Antropologia e saúde: traçando identidade e explorando fronteira. Rio de Janeiro: Fiocruz; Relume Dumará, 1998.

BARROS, Sônia Maria Oliveira. Enfermagem obstétrica e ginecológica: guia para a prática assistencial. 1. ed. São Paulo: Roca, 2002.

BRASIL. Constituição da República Federativa do Brasil. Brasília-DF, 1988. Disponível em: http://www. planalto.gov.br/ccivil_03/constituicao/constituicao.htm. Acesso em: 20 out. 2020.

COIMBRA JR., Carlos E. A.; GARNELO, Luiza. Questões de saúde reprodutiva da mulher indígena no Brasil. Porto Velho: Fiocruz, 2003

FACHIN, Odília. Fundamentos de metodologia. 4. ed. São Paulo: Saraiva, 2005.

FORTES, Paulo Antônio de Carvalho. Ética, direitos dos usuários e políticas de humanização da atenção à saúde. Saúde e Sociedade, São Paulo, v. 13, n. 3, p. 30-5, 2004. Disponível em: https://www.scielo.br/j/ sausoc/a/8GZ4zMCW6FhzZZw7CzdtF4n/?lang=pt. Acesso em: 21 out. 2021.

GOOGLE. Localização do território indígena Tapuia. Google Maps, 2020. Disponível em: https://www. google.com.br/maps/@-15.0579969,-49.9022366,26489m/data=!3m1!1e3. Acesso em: 21 out. 2021.

GUSDORF, George. Passado presente, futuro da pesquisa interdisciplinar. Tempo Brasileiro, Rio de Janeiro, n. 121,1995, p. $7-27$.

INSTITUTO BRASILEIRO DE PESQUISA E GEOGRAFIA [IBGE]. Os indígenas no censo demográfico. IBGE, Brasília-DF, 2010. Disponível em: http://indigenas.ibge.gov.br/estudos-especiais-3/o-brasil-indigena/osindigenas-no-censo-demografico-2010. Acesso em: 12 abr. 2016.

JOSÉ NETO, Joaquim. Jovens tapuios do carretão: processos educativos de reconstrução de identidade indígena. 2004. Dissertação (Mestrado em Educação) - Universidade Católica de Goiás, Goiânia, GO, 2004.

LANGDON, Esther Jean; WIIK, Flávio Braune. Antropologia, saúde e doença: uma introdução ao conceito de cultura aplicado às ciências da saúde. Revista Latino-Americana de Enfermagem Ribeirão Preto, v. 18, n. 3, p. 459-66, 2010.

LARAIA, Roque de Barros. Cultura: um conceito antropológico. Rio de Janeiro: Jorge Zahar, 2009.

LAZARIN, R. H. A. O aldeamento Carretão: duas histórias. 1985. Dissertação (Mestrado em Antropologia Social) - Universidade de Brasília, Brasília-DF, 1985.

LIDÓRIO, Ronaldo. Etnias indígenas brasileiras: relatório 2010. Indígena AMTB, Manaus, 2010 Disponível em http://www.indigena.org.br/v1/index.php?option=com_content\&view=article\&id=7:relatorio2010\& catid=1:banco-de-dados\&ltemid=3. Acesso em: 27 abr. 2016.

MACHADO, Maria das Dores de Jesus. Diferenças intra-urbanas da saúde em Belém, Pará. 2004. Tese (Doutorado em Desenvolvimento Sustentável do Trópico Úmido) - Universidade do Pará, Belém, Pará, 2004. 311 p. 
MARCONI, Marina de Andrade; PRESOTTO, Zelia Maria Neves. Antropologia: uma introdução. 7. ed. São Paulo: Atlas, 2010.

MARRONI, Denize. A importância da antropologia na saúde. Saúde Coletiva, Barueri, v. 4, n. 16, [s.p.], jul./ ago. 2007. Disponível em: https://www.redalyc.org/pdf/842/84201602.pdf. Acesso em: 21 out. 2021.

MAZZUOLI, Valerio de Oliveira (Org.). Constituição Federal. 13. ed. rev. ampl. e atual. São Paulo: Editora Revista dos Tribunais, 2015. (Coletânea de direito internacional)

MORAES, Alexandre. Direito Constitucional. 13. ed. São Paulo: Atlas, 2003.

PALHETA, Rosiane Pinheiro; FERREIRA, Reuly Silva. Fazer e pensar a saúde: os povos indígenas no Amazonas. In: JORNADA INTERNACIONAL DE POLÍTICAS PÚBLICAS, 23-26 ago. 2011, São Luís. Anais [...]. São Paulo: FAPEAM, 2011. Disponível em: http://www.joinpp.ufma.br/jornadas/joinpp2011/CdVjornada/. Acesso em: 21 out. 2021.

RAYNAUT, Claude. Interfaces entre a Antropologia e a Saúde: em busca de novas abordagens conceituais. Revista Gaúcha de Enfermagem, Porto Alegre, v. 27, n. 2, p. 149-65, 2006.

RICHARDSON, Roberto Jarry. Pesquisa social: métodos e técnicas. São Paulo: Atlas, 2003.

SILVA, Isabela Dantas; SILVEIRA, Maria de Fátima Araújo. A humanização e a formação do profissional em fisioterapia. Ciência \& Saúde Coletiva, Rio de Janeiro, v. 16, supp.1, p. 1535-46, 2011. Disponível em: https://www.scielo.br/j/csc/a/dJfwdfzVc4nVysSC7HSNY6R/?lang=pt. Acesso em: 21 out. 2021.

SILVA, Lorrane Gomes. A luta pela terra, a luta pela vida: a interveniência das Políticas Públicas no território do povo indígena Tapuia em Goiás. Ateliê Geográfico, Goiânia, v. 7, n. 3, p. 164-87, 2013.

SILVA, L. G.; VASCONCELOS, E. H. B. Os Tapuia: uma história de resistências e esperança. Tarairiú, Campina Grande, ano 3, n. 4, abr./maio 2012.

SILVA, Rose Mary Costa Rosa Andrade Silva; PEREIRA, Eliane Ramos; SANTO, Fátima Helena do Espírito; SILVA, Marcos Andrade. Cultura, saúde e enfermagem: o saber, o direito e o fazer crítico-humano. Revista Eletrônica de Enfermagem, Goiânia, v. 10, n. 4, p. 1165-71. 2008.

TEIXEIRA, Carla Costa; SILVA, Cristina Dias. Antropologia e saúde indígena: mapeando marcos de reflexão e interfaces de ação. Anuário Antropológico, Brasília, v. 38, n. 1, p. 35-57, 2013. Disponível em: https:// journals.openedition.org/aa/374. Acesso em: 21 out. 2021.

UCHÔA, Elizabeth; VIDAL, Jean Michel. Antropologia Médica: elementos conceituais e metodológicos para uma abordagem da saúde e da doença. Cadernos de Saúde Pública, Rio de Janeiro, v. 10, n. 4, p. 497-504, 1994.

VERANI, Cibeli; MORGADO, Anastácio. Fatores culturais associados à doença da reclusão do alto Xingu (Brasil Central). Caderno de Saúde Pública, Rio de Janeiro, v. 7, n. 4, p. 515-37, 1991. Disponível em: https:// www.scielo.br/j/csp/a/6XWT5W3SdSYPLw6NGTcTCkb/?lang=pt. Acesso em: 21 out. 2021.

\section{Sobre os autores:}

Valtecino Eufrásio Leal: Doutor em Direito pela Faculdade Autônoma de Direito (FADISP). Advogado, pesquisador e professor na Universidade Corporativa da Polícia Rodoviária Federal (UniPRF). E-mail: valtecino@gmail.com, Orcid: http://orcid.org/0000-0003-4324-0285 
Geruza Silva de Oliveira Vieira: Doutora em Sociologia pela Universidade Federal de Goiás (UFG). Pesquisadora e professora na Universidade Federal de Mato Grosso (UFMT). E-mail: geruza.vieira@ufmt.br, Orcid: http://orcid.org/0000-0002-4196-9235

HelmerMarra Rodrigues: Bacharel em Direito pelaUniversidade Evangélica de Goiás (UniEVANGÉLICA). Pesquisador. E-mail: helmer.marra@hotmail.com, Orcid: http://orcid.org/0000-0001-6986-389X

Maria Abadia da Silva: Bacharel em enfermagem pelo Centro Universitário do Cerrado de Patrocínio (UNICERP). Especialista em Enfermagem do Trabalho pelo Centro de Estudos de Enfermagem e Nutrição (CEEN). E-mail: abadiah1@hotmail.com, Orcid: https://orcid.org/0000-0001-6535-6452 
